
управление ФББОУ ВО «Дагестанский государственный университет», e-mail: maryam-gadzhieva-1994@mail.ru

\title{
РЕСУРСНО-ИННОВАЦИОННОЕ РАЗВИТИЕ РЕГИОНА
}

\begin{abstract}
Аннотауия. Џель работы. $B$ статье рассматриваются характеристики ресурсноинновационного развития как оптимальной стратегии развития для региона, сочетающей использование природно-ресурсного потенциала региона и преимущлества инновационного развития. Анализируются возможности ресурсно-инновационного развития для Республики Дагестан. Метод или методология проведения работы. Проведен эмпирический анализ и ста-

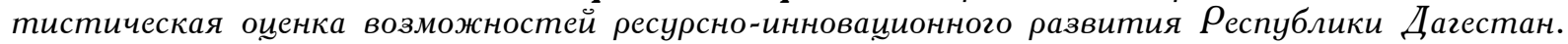
результаты. Благодаря работам Института геологии было установлено, что республика имеет перспективу на появление миоценовых отложений на титан, ииркон и благородные металль - золото, платину и серебро. Караган-чокракские мелкозернистые квариевые песчаники, простирающиеся на площлади более 500 кв. км, являются своеобразным сырьем титана, циркона, золота, платины, а обогащенный квариевый песок может служить сырьем для стекольной промышленности. Область применения результатов. Результаты проведенного исследования могут быть использованы с цеелью обеспечения стабильного сочиальноэкономического развития региона, в т. ч. и после истощцения его минерально-сырьевого потенииала. Выводы. Оптимальным вариантом для ресурсного региона является стратегия ресурсно-инновационного развития, которая сочетает использование богатейшего природноресурсного потенциала региона и преимущества инновационного развития. В основе ресурсноинновационного развития находится сырьевой сектор, функиионирующий на инновационных началах, что создает стимуль для формирования и развития в регионе высокотехнологичного сервисного сектора, производств глубокой переработки и научно-образовательного комплек$c a$.
\end{abstract}

Ключевые слова: ресурсно-инновационное развитие, ресурсы, регион, стратегия, сырьевой секmop.

GADZHIEVA MARYAM SHAHBANOVNA master's student of the faculty of Management, Department of State and municipal Management management $O F$ the Dagestan state University, e-mail: maryam-gadzhieva-1994@mail.ru

\section{RESOURCE AND INNOVATIVE DEVELOPMENT OF THE REGION}

Abstract. Purpose of work. The article considers the characteristics of resource-innovative development as an optimal development strategy for the region, combining the use of the natural resource potential of the region and the advantages of innovative development. The possibilities of resource and innovative development for the Republic of Dagestan are analyzed. Method or methodology of the work. An empirical analysis and statistical assessment of the possibilities of resource and innovative development of the Republic of Dagestan is carried out. Results. Thanks to the work of the Institute of Geology, it was established that the Republic has a prospect for the appearance of Miocene deposits on titanium, zircon and precious metals - gold, platinum and silver. Karagan-Chokrak fine-grained quartz sandstones extending over an area of more than $500 \mathrm{sq} . \mathrm{km}$, are a kind of raw material of titanium, zircon, gold, platinum, and enriched quartz sand can serve as a raw material for the glass industry. Scope of the results. The results of the research can be used to ensure stable socio-economic development of the region, including after the depletion of its mineral resource potential. Conclusions. The best option for a resource region is a strategy of resource-innovative development, which combines the use of the region's rich natural resource potential and the advantages of innovative development. Resource and innovative development is based on the raw materials sector, which operates on an innovative basis, which creates incentives for the formation and development of a high-tech service sector, deep processing industries, and a scientific and educational complex in the region.

Keywords: resource and innovative development, resources, region, strategy, raw materials sector. 
Введение. Ресурсно-инновационное развитие подразумевает под собой объединение потенциала добывающей промышленности и непосредственно науки для эффективного и комплексного освоения природно-ресурсной базы региона, формирование сбалансированной структуры экономики региона и создание основы для стабильного социально-экономического развития. Ресурсно-инновационное развитие не противопоставляет ресурсы и инновации по принципу «или-или», а соединяет их, умножая возможности и тех, и других [8].

Методы исследования. В процессе исследования использовались методы эмпирического и статистического анализа ресурсного потенциала региона (на примере Республики Дагестан). Это предполагает анализ собранной информационной базы, которая включает данные из архивов, отчётов, газет, журналов и т. д.

Результаты. Применяя новые технологии для эффективной и комплексной добычи сырьевых ресурсов, он становится драйвером инновационного развития, поскольку затем инвестиции и спрос на инновации естественным образом переходят в отрасли более высоких переделов, а также в обслуживающие и сервисные производства [13, с.79].

Инновационное развитие сырьевого сектора уже само по себе будет иметь значительные социально-экономические эффекты для региона, так как позволит существенно увеличить срок разработки месторождений, повысить эффективность использования природных ресурсов и снизить экологический ущерб [4, с. 26]. При этом инновационная активность сырьевого сектора неизбежно формирует спрос на оборудование и технику, новые материалы, сервисные услуги и т. п. Это, в свою очередь, создает условия для развития в регионе сервисного и обслуживающего сектора, в т. ч. его высокотехнологичного сегмента.

Также ресурсно-инновационное развитие предполагает создание в регионе производств глубокой переработки сырьевых ресурсов. Наибольшей социально-экономической эффективностью обладает развитие в ресурсных регионах инновационных производств глубокой переработки сырья, имеющих в своей структуре несколько технологически связанных переделов [3, с. 62]. Так, например, цена на продукцию газохимических производств в 10 и более раз превышает стоимость природного газа [2, с.106].

Однако основным условием ресурсно-инновационного развития является построение сильных взаимосвязей сырьевого сектора с экономикой региона. В настоящее же время во многих сырьевых регионах формируется своеобразный добывающий анклав, характеризующийся слабой включенностью сырьевого сектора в региональную экономику и его преимущественной ориентацией на сотрудничество с зарубежными компаниями [5, с. 92]. В связи с этим ресурсно-инновационное развитие региона требует соответствующих усилий со стороны региональных органов власти и разработки адекватного механизма управления данными процессами.

Дагестан является одним из старейших нефтегазодобывающих районов России, однако со-

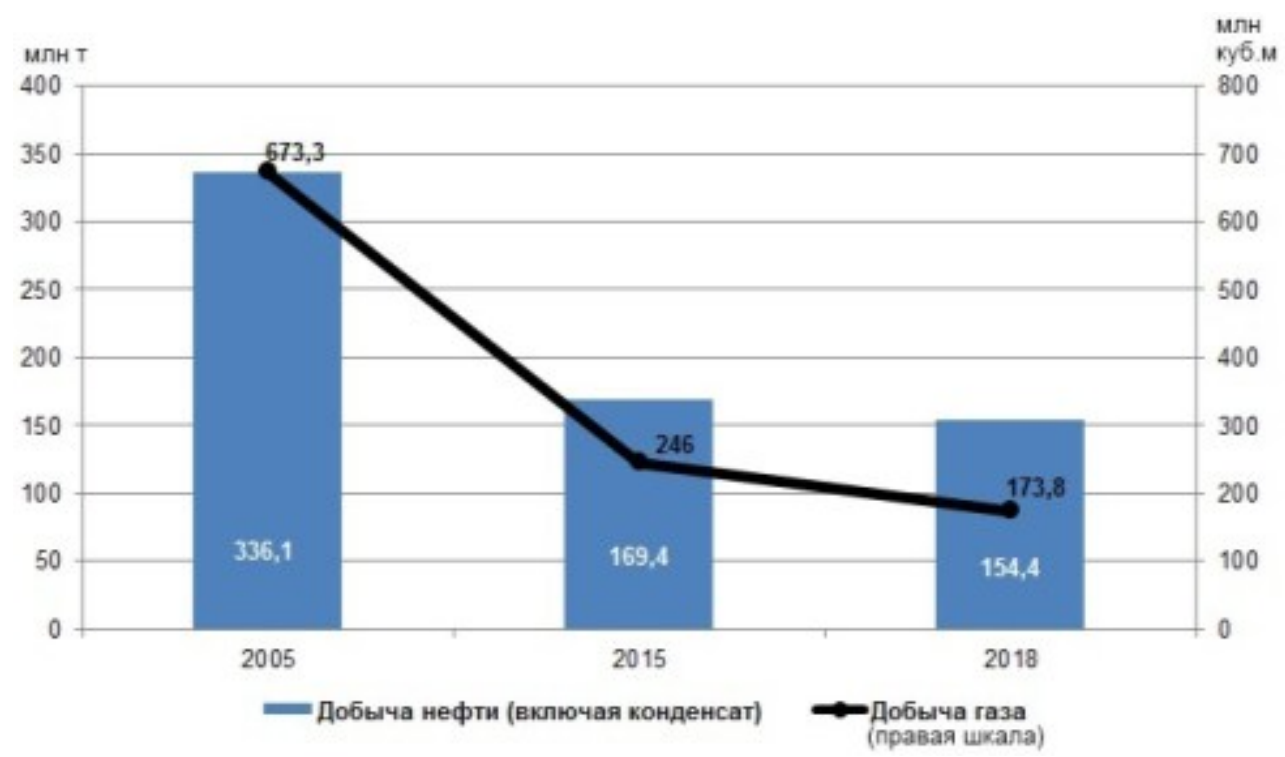

Puc. 1. Добыча нефти и газа в Дагестане [19]. 
временный уровень добычи нефти и газа не соответствует потенциальным возможностям республики. Нефтегазодобывающая отрасль Дагестана в своей истории пережила несколько подъемов и спадов (рис.). Максимальная годовая добыча в Дагестане достигнута в 1970 г. Тогда было добыто 2 млн 178 тыс. тонн нефти и 1,6 млрд кубических метров газа. С 1994 г. открыто лишь одно нефтегазовое месторождение «Новая надежда» в районе ВосточноМанычского прогиба, на границе Дагестана и Калмыкии.

Разведанные запасы и прогнозные ресурсы нефти Дагестана составляют 506 млн тонн. А труднодоступные регионы высокогорной части республики - Главный Кавказский, Боковой хребты - изучены лучше, чем легкодоступные предгорные части.

Такое положение обусловлено тем, что в середине прошлого века ставку делали на рудное сырье, а металлогенические зоны расположены именно в пределах высокогорья, куда и вкладывали основные ассигнования. Было разведано месторождение Кизил-Дере, несмотря на то что дефицит меди в стране не ощущался как на момент разведки месторождения, так и в настоящее время.

Благодаря работам Института геологии было установлено, что республика имеет перспективу появления миоценовых отложений титана, циркона и благородных металлов - золота, платины и серебра.

Караган-чокракские мелкозернистые кварцевые песчаники, простирающиеся на площади более 500 кв. км, являются своеобразным сырьем титана, циркона, золота, платины, а обогащенный кварцевый песок может служить сырьем для стекольной промышленности.

Под механизмом ресурсно-инновационного развития мы будем понимать систему взаимосвязанных элементов, нацеленных на эффективное и комплексное освоение ресурсного потенциала региона на инновационной основе, структурную модернизацию промышленности региона за счет развития инновационных и высокотехнологичных отраслей и преобразование экономического потенциала невозобновляемых природных ресурсов в воспроизводимый потенциал на основе знаний и новых технологий.

Учитывая многоаспектный характер проблемы, представляется, что механизм ресурсноинновационного развития должен включать в себя систему взаимосвязанных механизмов низшего порядка (подмеханизмов), направленных на решение отдельных задач и выполнение конкретных функций. Основными элементами механизма ресурсно-инновационного развития региона являются:

- механизм инновационного развития сырьевого сектора и повышения социальноэкономической эффективности проектов освоения минерально-сырьевых ресурсов;

- механизм формирования и развития в регионе высокотехнологичного сервисного сектоpa;

- механизм развития отраслей глубокой переработки минерально-сырьевых и топливноэнергетических ресурсов.

- механизм активизации в регионе деловой активности и инновационной деятельности.

Ресурсно-инновационное развитие региона требует в первую очередь создания общих условий для активизации деловой активности и инновационной деятельности в регионе. В качестве основных таких условий следует выделить наличие благоприятного инвестиционного климата, формирование региональной инновационной системы, обеспечивающей взаимодействие между разработчиками прикладных инноваций и их потребителями, и формирование кадрового потенциала для сервисного, перерабатывающего и сырьевого секторов экономики.

Инвестиционным климатом следует управлять путем целенаправленного воздействия на факторы, его формирующие. В первую очередь необходимо воздействовать на те факторы инвестиционного климата, которые будут благоприятствовать реализации приоритетных инвестиционных проектов. Так, для Республики Дагестан требуется улучшение организационноправовых факторов инвестиционного климата и уровня развития транспортной инфраструктуры.

Ресурсно-инновационное развитие региона требует формирования соответствующей региональной инновационной системы, которая должна быть направлена на обеспечение доступности необходимых технологий и инноваций для промышленного сектора, поддержку развития прикладных исследований и разработок для сервисного, перерабатывающего и сырьевого сек- 
торов и развитие кооперации между научными организациями и данными секторами. Иными словами, региональная инновационная система должна быть строго ориентирована на развитие приоритетных секторов экономики региона.

Механизм инновационного развития сырьевого сектора должен строиться на гибком сочетании мер стимулирования и принуждения. И значительная роль здесь должна отводиться порядку предоставления недр в пользование. Инструментом прямого воздействия является лицензия на право пользования недрами, в которой могут быть закреплены объемы добычи, сроки и технические условия освоения месторождений, принуждающие недропользователей использовать инновационные технологии. Способствовать принудительному использованию новых технологий может введение эффективного технического регулирования.

Так, в мировой практике технологии, применяемые для разработки месторождений, проходят государственную экспертизу и отражаются в соответствующих нормах и правилах. Также необходимо сформировать эффективную систему государственного контроля за проведением геологоразведочных и добычных работ, за выполнением условий лицензий и договоров на право пользования участками недр. Такой мониторинг и контроль наиболее целесообразно осуществлять на региональном уровне.

Учитывая богатейшую ресурсно-сырьевую базу республики, стратегические цели Российской Федерации и истощение нефтегазовых месторождений в основных добывающих регионах, сырьевая специализация Республики Дагестан не может быть существенно изменена в среднесрочной перспективе. В связи с этим для республики актуальным является переход к ресурсно-инновационному развитию. Как было указано выше, ресурсно-инновационное развитие предполагает:

- инновационное развитие сырьевого сектора и усиление его взаимосвязей с региональной экономикой;

- развитие сервисных и обслуживающих отраслей;

- развитие отраслей глубокой переработки ресурсов;

- развитие научно-образовательного комплекса региона.

Необходимость инновационного развития сырьевого сектора Республики Дагестан обуславливается:

- сложностью минерально-сырьевой базы и трудной извлекаемостью значительной части запасов;

- нахождением многих месторождений в удаленных труднодоступных районах с неразвитой транспортной инфраструктурой и тяжелыми природно-климатическими условиями;

- низким уровнем извлечения минерально-сырьевых ресурсов;

- обострением экологических проблем, связанных с добычей полезных ископаемых.

Выводы. В целях решения проблем ресурсно-инновационного развития Республики Дагестан необходимо волевое решение руководства республики, изменение законодательной базы по недропользованию, а также привлечение профессионалов к разработке проектов при проведении поисково-оценочных и геологоразведочных работ. В противном случае мы рискуем в ближайшее время оказаться в глубоком экономическом кризисе, поскольку предпринятые экстренные меры по проведению крупномасштабных геологических работ приняты только сегодня. Лишь через несколько лет полученные результаты можно будет использовать в добыче полезных ископаемых.

Таким образом, в Республике Дагестан существуют широкие возможности для ресурсноинновационного развития, однако наличие ряда ограничивающих факторов, таких, как ориентация сырьевого сектора на использование зарубежных технологий и оборудования, высокий объем требующихся инвестиций на реализацию приоритетных проектов и низкая обеспеченность предприятий республики собственными финансовыми ресурсами, удаленность региона от основных потребителей, требует соответствующих усилий со стороны региональных органов власти и разработки механизма управления ресурсно-инновационным развитием.

Литература

1. Высочанская Е. С., Скодорова Л. К. Модель инноваџионного развития региона // Информационные технологии в моделировании и управлении: подходы, методы, решения. Материаль II Всероссийской научной конференции с международным участием. В 2 частях. - 2019. - C. 357-364. 
2. Каминский А. В. Развитие глубокой переработки газа в мировой экономике // Российский внешнеэкономический вестник. - 2013. - № 9. - C.106-114.

3. Крюков В. А. Социально-экономическая «капитализаџия» сырьевого потенщиала России // ЭКО. 2015. - № 2. - C. 62-75.

4. Крюков В. А. Сырьевые территории в новой институцииональной реальности // Пространственная экономика. - 2014. - № 4. - C. 26-60.

5. Левин С. Н., Каган Е. С., Саблин К. С. Регионы «ресурсного типа» в современной российской экономике // Journalofinstitutionalstudies (Журнал институциональных исследований). - 2015. - Том 7. - № 3. C. $92-101$.

6. Луцевич А. Интеллектуальные ресурсы в инновационном развитии регионов // Наука и инновации. 2019. - № 8 (198). - C. 34-38.

7. Манукян М. М. Факторы, влияющие на развитие инноваџионной деятельности промышленного комплекса региона // Вестник Самарского университета. Экономика и управление. - 2019. - T. 10. - № 1. C. 31-35.

8. Мастепанов А. М. И еще раз о необходимости перехода экономики России на ресурсноинновационньй путь развития // Бурение и нефть. - 2014. - № 11.

9. Нагаева О. С. Управление инвестиционной привлекательностью в иелях обеспечения ресурсноинновачионного развития региона: монография / О. С. Нагаева, Г. И. Поподько, С. Л. Улина. - Красноярск: Сиб. Федер. Уни-т, 2016. - 172 с.

10. Ресурсные регионы России в «новой реальности» / под ред. акад. Кулешова В. В. - Новосибирск: Изд -во ИЭОПП СО РАН, 2017. - 308 c.

11. Севастьянова А. Е. Подходы к обоснованию инновачионной политики сырьевых регионов // Журнал Сибирского федерального университета. Серия: гуманитарные науки. - 2015. - T. 8. - С. 98-107.

12. Силкин В., Токарев А., Шмат В. Сорванный стоп-кран // Эксперт-Сибирь. - 2013. - № 23. - С. $11-$ 15 .

13. Симонова Л. М., Черкашов Е. М. Методологические аспекты разработки модели региональной инновационной системы // Вестник Тюменского государственного университета. - 2012. - № 11. - C. 79 86.

14. Токарев А. Н. Нефтесервис как основа инновационного развития нефтяной промышленности // Инновации и образование. - 2014. - № 4. - C. 91-99.

15. Шамина Л. К. Инновационные методы прогнозирования развития региона в условиях развития циифровой экономики // Развитие ичифровой экономики в условиях деглобализаџии и рецессии Алетдинова А. А., Алехина Д. А., Андрухова О. В., Бабкин А. В., Баирова Н. И., Богданова Р. М., Борисов А. А., Бочкова С. В., Быковская Е. В., Вертакова Ю. В., Волкова А. А., Воронов Д. В., Гарифова Л. Ф., Глущенко М. Е., Голденова В. С., Григорьева Е. А., Ермоленко О. Д., Захарова Ю. В., Иванов А. А., Измалкова С. А. и др. Санкт-Петербург, 2019. - С. 227-253.

16. Шалаева Т. А. Зарубежный и отечественный опыт обеспечения инновачионного развития региона // Контентус. - 2019. - № 6 (83). - C. 32-37.

17. Эдер Л. В., Саблин К. С., Проворная И. В. Научные подходы к обоснованию приоритетных инноваиионно-технологических направлений пространственной спеииализаиии ресурсных регионов России // Фундаментальные исследования. - 2017. - № 5. - С. 220-224.

18. Офиииальный сайт Министерства промышленности и торговли Российской Федераиии. [Электронный ресурс]. Режим доступа: http://minpromtorg.gov.ru/opendata/, свободный. - Загл. с экрана.

19. Офиџиальный сайт Министерства промышленности и энергетики Республики Дагестан. [Электронный ресурс]. Режим доступа: http://www.minpromdag.ru/, свободный. - Загл. с экрана.

20. Офичиальный сайт Территориального органа Федеральной службы государственной статистики по Республике Дагестан. [Электронный ресурс]. Режим доступа: https://dagstat.gks.ru/, cвободный. Загл. с экрана.

\section{References:}

1. Vysochanskaya E. S., Skodorova L. K. Model' innovacionnogo razvitiya regiona // Informacionnye tekhnologii v modelirovanii i upravlenii: podhody, metody, resheniya. Materialy II Vserossijskoj nauchnoj konferencii s mezhdunarodnym uchastiem. V 2 chastyah. - 2019. - S. 357-364.

2. Kaminskij A. V. Razvitie glubokoj pererabotki gaza v mirovoj ekonomike // Rossijskij vneshneekonomicheskij vestnik. - 2013. - № 9. - S.106-114.

3. Kryukov V. A. Social'no-ekonomicheskaya «kapitalizaciya» syr'evogo potenciala Rossii // EKO. - 2015. № 2. - S. 62-75.

4. Kryukov V. A. Syr'evye territorii v novoj institucional'noj real'nosti // Prostranstvennaya ekonomika. 2014. - № 4. - S. 26-60.

5. Levin S. N., Kagan E. S., Sablin K. S. Regiony «resursnogo tipa» v sovremennoj rossijskoj ekonomike // Journalofinstitutionalstudies (ZHurnal institucional'nyh issledovanij). - 2015. - Tom 7. - № 3. - S. 92-101.

6. Lucevich A. Intellektual'nye resursy $v$ innovacionnom razvitii regionov // Nauka i innovacii. -2019 . - № 8 (198). - S. 34-38.

7. Manukyan M. M. Faktory, vliyayushchie na razvitie innovacionnoj deyatel'nosti promyshlennogo kompleksa regiona // Vestnik Samarskogo universiteta. Ekonomika i upravlenie. - 2019. - T. 10. - № 1. - S. 31-35.

8. Mastepanov A. M. I eshche raz o neobhodimosti perekhoda ekonomiki Rossii na resursno-innovacionnyj put razvitiya // Burenie i neft'. - 2014. - № 11 .

9. Nagaeva O. S. Upravlenie investicionnoj privlekatel'nost'yu v celyah obespecheniya resursno- 
ГАДЖИЕВА М.Ш.

РЕСУРСНО-ИННОВАЦИОННОЕ РАЗВИТИЕ РЕГИОНА

innovacionnogo razvitiya regiona: monografiya / O. S. Nagaeva, G. I. Popod'ko, S. L. Ulina. - Krasnoyarsk: Sib. Feder. Uni-t, 2016. - 172 s.

10. Resursnye regiony Rossii v «novoj real'nosti» / pod red. akad. Kuleshova V. V. - Novosibirsk: Izd-vo IEOPP SO RAN, 2017. - 308 s.

11. Sevast'yanova A. E. Podhody k obosnovaniyu innovacionnoj politiki syr'evyh regionov // ZHurnal Sibirskogo federal'nogo universiteta. Seriya: gumanitarnye nauki. - 2015. - T. 8. - S. 98-107.

12. Silkin V., Tokarev A., SHmat V. Sorvannyj stop-kran // Ekspert-Sibir'. - 2013. - № 23. - S. 11-15.

13. Simonova L. M., CHerkashov E. M. Metodologicheskie aspekty razrabotki modeli regional'noj innovacionnoj sistemy // Vestnik Tyumenskogo gosudarstvennogo universiteta. - 2012. - № 11. - S. 79-86.

14. Tokarev A. N. Nefteservis kak osnova innovacionnogo razvitiya neftyanoj promyshlennosti // Innovacii $i$ obrazovanie. - 2014. - № 4. - S. 91-99.

15. SHamina L. K. Innovacionnye metody prognozirovaniya razvitiya regiona v usloviyah razvitiya cifrovoj ekonomiki // Razvitie cifrovoj ekonomiki v usloviyah deglobalizacii i recessii Aletdinova A. A., Alekhina D. A., Andruhova O. V., Babkin A. V., Bairova N. I., Bogdanova R. M., Borisov A. A., Bochkova S. V., Bykovskaya E. V., Vertakova YU. V., Volkova A. A., Voronov D. V., Garifova L. F., Glushchenko M. E., Goldenova V. S., Grigor'eva E. A., Ermolenko O. D., Zaharova YU. V., Ivanov A. A., Izmalkova S. A. i dr. Sankt-Peterburg, 2019. - S. 227-253

16. SHalaeva T. A. Zarubezhnyj i otechestvennyj opyt obespecheniya innovacionnogo razvitiya regiona // Kontentus. - 2019. - № 6 (83). - S. 32-37.

17. Eder L. V., Sablin K. S., Provornaya I. V. Nauchnye podhody k obosnovaniyu prioritetnyh innovacionnotekhnologicheskih napravlenij prostranstvennoj specializacii resursnyh regionov Rossii // Fundamental'nye issledovaniya. - 2017. - № 5. - S. 220-224.

18. Oficial'nyj sajt Ministerstva promyshlennosti i torgovli Rossijskoj Federacii. [Elektronnyj resurs]. Rezhim dostupa: http://minpromtorg.gov.ru/opendata/, svobodnyj. - Zagl. s ekrana.

19. Oficial'nyj sajt Ministerstva promyshlennosti $i$ energetiki Respubliki Dagestan. [Elektronnyj resurs]. Rezhim dostupa: http://www.minpromdag.ru/, svobodnyj. - Zagl. s ekrana.

20. Oficial'nyj sajt Territorial'nogo organa Federal'noj sluzhby gosudarstvennoj statistiki po Respublike Dagestan. [Elektronnyj resurs]. Rezhim dostupa: https://dagstat.gks.ru/, svobodnyj. - Zagl. s ekrana. 